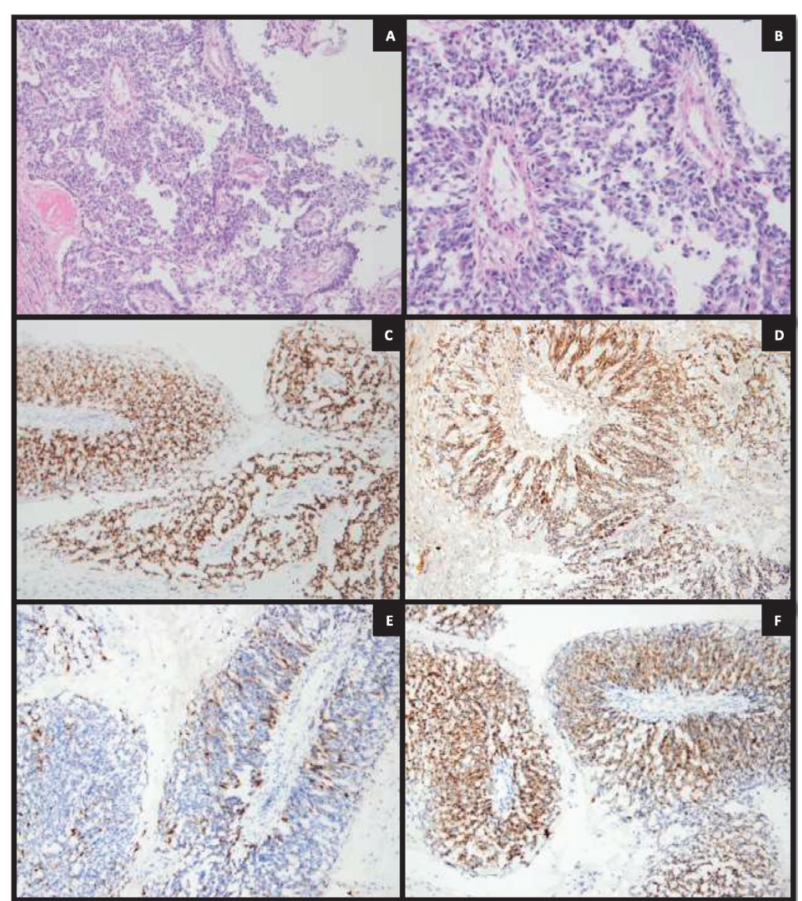

Abstract 1120 Figure 2

the left side of vulva, inguinal palpation was normal, and no abnormalities was detected in the internal genitalia (figure 1). In the pelvic MRI a $69 * 65 * 55 \mathrm{~mm}$ vulvar mass was reported, and this mass showed a FDG uptake of 11.5 SUVmax in the PET- CT. No distant and nodal uptake was detected. Also, upper, and lower gastrointestinal endoscopies were reported normal.

A vulvar mass resection and left superficial inguinal lymphadenectomy was performed. During the operation the mass was mobile and no invasion with other tissues was detected. The final pathology specimen was diagnosed as yolk sac tumour of the vulva, all surgical margins and lymph nodes were negative (figure 2). The patient was given four cycles of Bleomycin, Etoposide and Cisplatin (BEP) chemotherapy. She is being regularly examined every three months and no relapse has been detected in 10 months.

Conclusion* Primary YST of the vulva is extremely rare and this case is the 16 . case in the literature. Local excision and adjuvant BEP chemotherapy should be the choice of treatment in these patients.

\section{STEP BY STEP RADICAL VULVECTOMY AND ANATOMICAL BOUNDARIES ON LIVE PATIENT}

I Selcuk* , F Kilic, O Ceylan, B Ersak, HR Yalcin. Ankara Şehir Hastanesi, Turkey

\subsection{6/ijgc-2021-ESG0.639}

Introduction/Background* To demonstrate the true anatomical boundaries and surgical technique for radical vulvectomy on a live patient.

Methodology This surgical video was recorded at Ankara City Hospital, where is an ESGO Accredited Gynecologic Oncology Center.
Result(s)* - A proper vulvar incision depending on the localization of the tumor with $2 \mathrm{~cm}$ lateral gross margin if possible is performed (close to the urethra and anus this margin will decrease to $1 \mathrm{~cm})$.

- The incision deepens down to the level of perineal membrane (the inferior fascia of the urogenital diaphragm which is superior to the superficial perineal space) by passing through the subcutaneous fatty tissue with creating dissection tunnels.

- At the cranial part of the dissection, the pubic periosteum is found and here, the suspensory ligament of clitoris with the dorsal artery of clitoris should be ligated.

- At the craniolateral part of the vulvar dissection, the adductor fascia is encountered.

- At the caudolateral part of the vulvar dissection, the perineal branches of the internal pudendal artery lie at the 5 and 7 o'clock positions of the vulva.

- At the caudal part of the vulvar dissection, the posterior vulvar tissue is dissected from the perineal body and here, the dissection proceeds over the rectovaginal septum.

- A circumferential vaginal inner incision encircling the vaginal introitus and lying superior to the external urethral meatus is performed, by the way the outer vulvar and inner vaginal incision are bounded. Here, a Foley catheter may secure the urethra.

- After excision of the vulvar tissue; if possible, the wound is closed primarily. First, the deep subcutaneous part is closed and the lateral margin of the vaginal introitus is sutured to the medial edge of the vulvar excision line.

- If it is not possible to close the wound with primary sutures, a flap reconstruction is performed.

Conclusion* The perineal arteries at 5 and 7 o'clock positions should be kept on mind while performing a radical vulvectomy and the deepness of the excision at the base of the tumor should extend to the level of the perineal membrane.

\section{STEP BY STEP INGUINOFEMORAL LYMPHADENECTOMY AND ANATOMICAL BOUNDARIES ON LIVE PATIENT}

I Selcuk*, F Kilic, O Ceylan, B Ersak, HR Yalcin. Ankara Şehir Hastanesi, Turkey

\subsection{6/ijgc-2021-ESG0.640}

Introduction/Background* To demonstrate the proper anatomical landmarks and surgical technique for inguinofemoral lymphadenectomy on a live patient.

Methodology This surgical video was recorded at Ankara City Hospital, an ESGO Accredited Gynecologic Oncology Center.

Result(s)* 1. The superficial inguinal lymph nodes are located between the Scarpa's fascia and fascia lata. The deep inguinofemoral lymph nodes are located below the fascia lata medial to the femoral vein.

2. After the groin incision, which is $2 \mathrm{~cm}$ below the inguinal ligament and parallel to it, the Camper's fascia is secured by identifying the Scarpa's fascia.

3. The superficial inguinal lymph nodes are dissected from the craniolateral part to the caudomedial part; between the superficial circumflex iliac vein laterally, superficial external pudendal vein medially, aponeurosis of the external oblique muscle cranially and inferomedial end of the inguinal ligament where it intersects with the adductor longus muscle caudally. 